\title{
Offshore Windmill Equipped with Semi-Submersible Platform with Spar-Buoy
}

\author{
Subhasharmini, V. Reddy Pavani, Shreya Prasanth, Arun Thomas Cherian
}

Abstract-The principle objective of this proposed project is to build a working model of a floating windmill with a semi-submersible platform of 1:71 downsize ratio, a Spar-buoy platform of 1:50 downsize ratio and to assess and analyse the challenges faced in the process of design and deployment, to assess, compare and record dynamic characteristics.

\section{INTRODUCTION}

Renewable energy plays an important role in providing trillions of people in developing countries with modern energy access that continues to depend on more traditional energy sources [2]. After the United States, China and Russia, India is the fourth largest consumer of energy in the world. India's energy consumption has been increasing at a relatively fast rate in recent years due to population growth and economic development. India's current centralized energy planning depends on sources of coal and fossil fuel. As energy demand increases, we need to look at the alternatives of conservative fossil fuels. Total installed capacity in the country is approximately $302 \mathrm{GW}$, of which (i) Non-renewable energy accounts for $79.8 \%$ (ii) Renewable energy represents $20.2 \%$. Wind power accounts for about $49.3 \%$, followed by solar (31.4\%), biomass power (12.6\%), according to recent statistics. Wind power is one of the future's most promising alternative energy technologies. Due to significant advances in turbine technology, the amount of energy produced by wind turbines has increased rapidly in recent years, making wind power economically compatible. There are two prominent methods to harness the wind which are Onshore and Offshore.

Revised Version Manuscript Received on 10 September, 2019.

Subhasharmini, V. SRM INSTITUTE OF SCIENCEAND TECHNOLOGY, Kattankulathur, Chennai- 603202, Tamil Nadu, India.(Email: subha.a.star@gmail.com)

Reddy Pavani, SRM INSTITUTE OF SCIENCEAND TECHNOLOGY, Kattankulathur, Chennai- 603202, Tamil Nadu, India.(Email: pavani_shankar@srmuniv.edu.in)

ShreyaPrasanth, SRM INSTITUTE OF SCIENCEAND TECHNOLOGY, Kattankulathur, Chennai- 603202, Tamil Nadu, India.(Email: shreyaprasanth_pr@srmuniv.edu.in)

Arun Thomas Cherian, SRM INSTITUTE OF SCIENCEAND TECHNOLOGY, Kattankulathur, Chennai- 603202, Tamil Nadu, India.(Email: arunthomas_ch@srmuniv.edu.in)

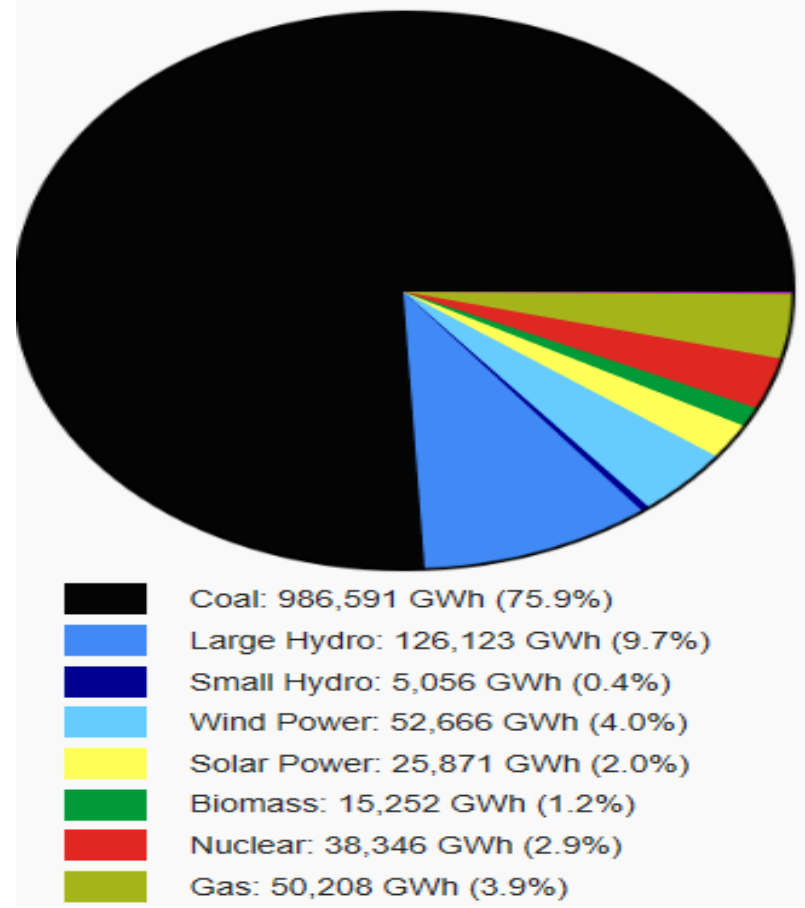

Fig 1. Installed energy capacity in India (2017-2018)

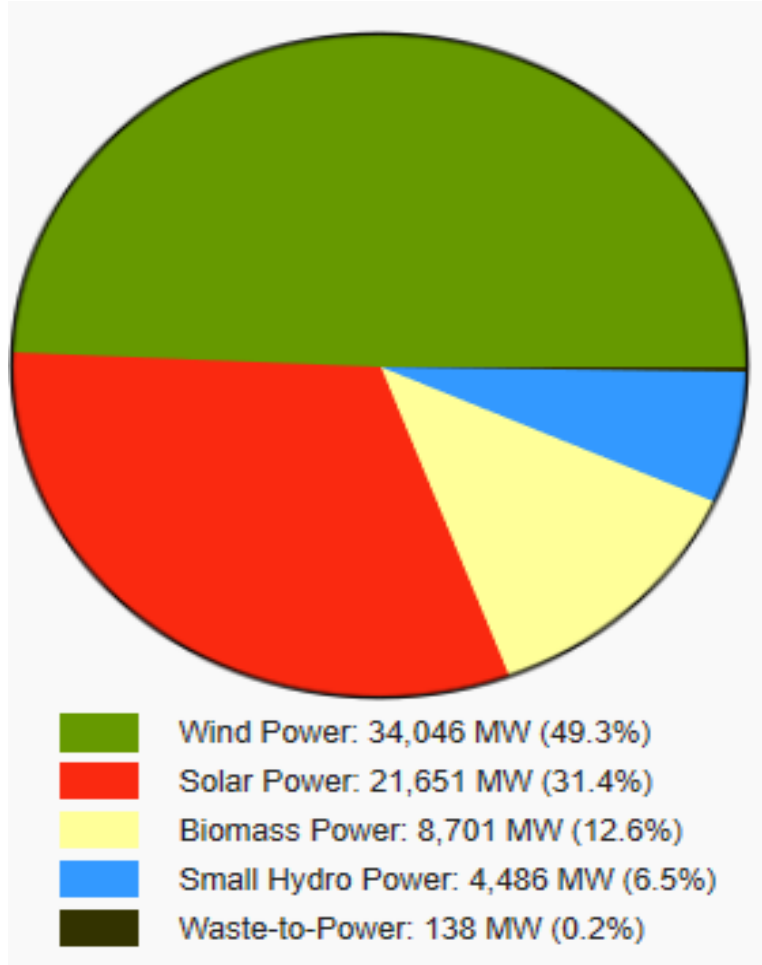

Fig 2.Installed capacity of renewable resources.

Published By: 
Wind energy is one of the future's most lucrative alternative energy technologies. Mainly due to substantial advances in wind technologies, the amount of electricity produced by wind turbines has increased rapidly over the past few years, making wind power economically compatible with fossil fuel energy sources.Wind energy accounts for about 49.3 percent of the overall clean energy capacity built in India. There are two notable wind harnessing methods that are onshore and offshore Fig. 3. There are also many windmill platform structures determined based on the structure and principle Fig 4. This article discusses about the distribution of the renewable resources and need of the clean wind energy and its contribution towards the modern power demands. It also describes the downsizing and testing of Semi-submersible and Spar-buoy platforms.

\section{MODEL DESCRIPTION\& RESULTS}

\section{A. Semi-submersible platform}

Semi-submersible platform is generally equipped with three, four or six legs. Semi-submersible type platforms have three pontoons of same height and one column in the centre which is less in diameter but also taller than the pontoons on which wind turbine is geometrically centred. The tower height has been reduced in proportion to the rotor blades to reduce the magnified vibration amplitudes which otherwise will result in the stability of the wind turbine. By considering the wind turbine dynamics, after observing many published design models, we have come to a conclusion that tower hub properties of HDPE above, we chose the same material to construct a tripod semi-submersible platform. The downsize ratio of the base is 71:1 with respect to one of our reference papers as shown in Fig 4.2,4.3. This design is modified by using an original existing model of higher scale and then downsizing it to a ratio which is compatible in 2 to $3 \mathrm{~m}$ water depth. The project utilises High Density Polyethylene (HDPE) pipes as the material for the platform. HDPE (density $=970 \mathrm{Kg} / \mathrm{m}^{3}$ ) is less dense than water and thus it can stay afloat in the sea. HDPE is also corrosion resistant and is able to withstand the high-pressure conditions.

\section{B. Spar-buoy platform}

Spar Buoy is a thin, tall buoy which floats upright in the water and has a small water plane area. It ranges in length from a few feet to 350 feet. These are used as oceanographic, wave measurement devices. Spar buoy is a type of platform that is used for both offshore windmills as well as offshore oil rigs. In our design, there are two aluminium poles to provide stability and a larger footprint to keep the structure stable. The structure consists of three aluminium blades, $120^{\circ}$ apart. The top-part is attached to a Nylon block. The Nylon block is sturdy and offers the features of being water-proof and air-tight. The cap is used to attach the top -part to the base. The base is made of a PVC pipe. Ballast which is made of steel, is then placed in this PVC pipe. There are 4 ballast that are put into the PVC base. The number of steel plates can be adjusted according to the required height of the ballast. The ballast helps in lowering the centre of gravity which allows the wind mill to stay upright and also provides required balance for the structure. The hub and blades are mounted on height to rotor blade length ratio is 1.18 . As we mentioned the

top of the Aluminium pole. The prototype model was designed based on the NREL baseline wind turbine, with a rotor diameter of $126 \mathrm{~m}$, a hub height of $90 \mathrm{~m}$ and a total weight of 700 metric tons rated to produce a power output of $5 \mathrm{MW}$. The turbine has a spar buoy platform with a draft of $60 \mathrm{~m}$ and a diameter of $14 \mathrm{~m}$. Froude scaling was used to the downsizing of the upscale model. Length measurements are reduced by 100:1 and weights and forces by 106:1 and 1010:1 for moments of inertia.

\section{IV.TESTING}

\section{A. Field testing}

The field test was carried out for three days in three different locations for Spar-buoy and Semi-submersible. Various parameters like voltage, current, shaft speed, lumen values are recorded

\section{B. Flotation test}

The flotation analysis for the developed model was carried for three consecutive days in a tank of depth $2 \mathrm{~m}$ and above, below water level are measured at different times of the day.

\section{REFERENCES}

1. REN21 (2010). "Renewables 2010 Global Status", Report p. 15

2. Thomas P. Mazarakos and Spyridon A. Mavrakos, "Experimental Investigation on Mooring Loads and Motions of A TLP Floating Wind Turbine"-Science direct, School of Naval Architecture and Marine Engineering, National Technical University of Athens

3. N.S. Cetin, M.A. Yurdusev, R. Ata and A,Ozdemir, "Assessment of Optimum Tip-Speed Ratio of Wind Turbines," Mathematical and computational Applications-Science direct, Vol.10, No.1, pp.147-154,2005

4. W. Musial, S. Butterfield and A. Boone," Feasibility of Floating Platform Systems for Wind Turbines"-Sciencedirect, Reno Nevada, January 5-8,2004

5. B.HBulder,Dr.A.Henderson,Dr.ir.R.H.M.Huijsmans,ir.J. M.Peeringa,ir.J.T.G.Pierik,ir.E.J.B.Snijders, Dr.ir. M.Th.vanHees,ir. G.H.Wijnants,ir. M.J. Wolf," Floating Offshore Wind-Turbine for Shallow Waters"-Sciencedirect, Energy Research canter of the Netherland

6. Mrs.K.SubhaSharmini, "Design, Development and Testing of a Down-Sized Offshore Windmill Floating Model"-Springer, SRM IST, Chennai, India

7. Daniele Shahri, Hassan Ghassemi, "Dynamic Response Analysis of a Floating Wind Turbine Tri-Floater type with Heave -Plate and mooring system", Sciencedirect, Amirkabir Institute of Technology, Tehran

8. Sambasivarao N, Amarnath $\mathrm{J}$ Purnachandrarao $\mathrm{V}$, "Congestion Management Using Facts Devices in Deregulated Power System", IJRET- International Journal of Research in Engineering and Technology, 2, 90-95, 2013

9. "GWEC Global Wind Statistics 2014" (PDF)- Global Wind Energy Council,10 February 2015

10. "Challenges in design of foundations for offshore wind turbines". The E\&T Energy and Power Hub. The E\&T Energy and Power Hub. 9 August 2017. 
11. "Windmill definition stating that a windmill is a mill or machine operated by the wind". Merriam-webster.com. 2012-08-31.

12. History of Wind Energy in Energy Encyclopedia vol. 6, page 422 - Sciencedirect, 2013

13. "All India installed capacity of power stations" (PDF)INWEA, March 2018

14. R. SrikanthSangeethaKandavel (29 January 2015). "Tapping the offshore wind"-The Hindu. Retrieved 30 April 2015

15. Evans, Annette; Strezov, Vladimir; Evans, Tim (June 2009). "Assessment of sustainability indicators for renewable energy technologies"-Sciencedirect, June 2009

16. Dynamic Model of a Semi-Submersible Platform for the Development of Ballast Control Systems Leandro Marques SamynJos'e Paulo V. S. Cunha- Sciencedirect, September 2009

17. "How Do Semisubmersibles Work?"- www.rigzone.com. Retrieved 2018-07-05.

18. Richard D'Souza State-of-the-art of spread moored systems for deepwater floating production platforms- offshore-mag.com, January 2002

19. Erin E. BachynskiTorgeirMoan "Design considerations for tension leg platform wind Turbines Author links open overlay panel" Volume 29, Issue 1, December 2012, Pages 89-114-Sciencedirect

20. C. M. Wang, T. Utsunomiya, S. C. Wee , Y. S. Choo "Research on floating wind turbines: a literature survey" Pages 267-277 - IES Journal, June 2010

21. E. Faguaga a, C.J. Pérez aN. Villarreal b, E.S. Rodriguez a, V. Alvarez, "Effect of water absorption on the dynamic mechanical properties of composites used for windmill blades"- Sciencedirect, 2012 